\section{SUCCESSFUL CASE OF OVARIOTOMY.}

By W. L. Wratisiaw, Esq., Visiting Surgeon to the London Home.

THE following case occurred lately in the practice of $\mathrm{Mr}$. I. B. Brown:-

J. B., aged 18, from Wisbeach, at the end of July 1859, after a slight attack of what was called "peritonitis", first perceived a swelling of the abdomen, low down on the right side. The medical man whom she consulted declared her to be pregnant, which she strongly denying, his partner saw her, and, after a careful examination, pronounced it to be ovarian dropsy. She then came up to a London hospital, where the opinion of pregnancy was endorsed by one of the physicians, and he even advised one of the pupils to listen for the foctal bruit. The physician-accoucheur, being consulted, pronounced it to be a bad form of ovarian disease, of such a kind as not to admit of treatment; especially condemning extirpation. She was subsequently sent to Mr. Baker Brown, who, on examination, pronounced it to be multilocular ovarian dropsy of rapid growth. He pointed out extirpation as the only remedy, telling her at the same time that the chances were against her recoverv. She, however, subsequently elected, her mother and friends consenting to have the operation performed. She was therefore admitted into the London Home, and put under a preparatory course of treatment, consisting of warm baths, alterative tonics, and mild aperients.

March 22, 1860. She was placed under the influence of chloroform, and Mr. Brown proceeded to operate. He made an incision, about four inches in length, from the umbilicus, and gradually cut down upon and opened the peritoneum. The cyst was exposed, and, on passing the hand round, it was found to have very few adhesions. It was then punctured with a large trocar; but, from the numerous cysts of which it was composed, as well as the thickness of the contained fluid, it could not be much reduced in size. The incision was therefore slightly extended, and the mass drawn out, the pedicle being long and narrow. A long needle, armed with double Indian twine, was passed through it, carefully avoiding the bloodvessels, and tied in two portions. The incision was then closed with iron-wire sutures at short intervals; the ligature of the pedicle, not the pedicle itself, being brought out at the lower extremity. Lint was placed over the cut, and a bandage round the abdomen, and she was removed to bed. About two hours afterwards, as she complained of some pain, she had a grain of opium as a suppository, and linseed-meal poultices anplied over the abdomen. In the evening the pulse was 106 ; she only complained of "throbbings". The opium suppository was ordered to be repeated as necessary.

March 23rd. She slept at intervals during the night. Early in the morning, she was three times sick. The pulse was 106 ; the tongue was slightly coated; the skin moist. She was ordered an effervescing mixture, with hydrocyanic acid. She took milk, barley-water, toast and water, and ice. The opium suppository was ordered to be applied when necessary.

After this, she went on well, and on May 3rd was quite well, and had gained flesh. The incision was firmly united on March 31; and on April 5, the pedicle came away. A small abscess was formed in the middle of the incision and was opened.

Mr. Brown did not use the clamp in this case, having found, in three previous successful cases, that vicarious menstruation took place from the incision where the pedicle adhered to the surface, causing much annoyance. Mr. Brown therefore fell back upon Dr. Clay's plan of using Indian twine, and allowing the pedicle to return into the pelvic cavity.

I may observe, having had charge of the five cases of ovari. otomy which have been operated on in the London Home during the past two years (three of which have been successful), that the plan of allowing the pedicle to be loose in the pelvic cavity, and not held up tight, as by the clamp, entirely does away with the "dragging", which has otherwise been much complained of by the patient.

Archer Street, Westbourne Grove.

UnIVERSTTy of London. Her Majesty has been pleased to nominate the Right Hon. Robert Lowe, Richard Quain, M.D., and James Paget, Esq., F.R.S., to vacancies in the Senate of this University, caused by the deaths of Bishop Maltby, Lord Macaulay, and Mr. M. T. Baines.

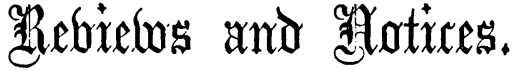

On Asthin; its Pathology and Treatientr. By Henry Hyde Salter, M.D., F.R.S., Fellow of the Royal College of Physicians; Assistant-Physician to Charing Cross Hospital, and Lecturer on Physiology and Pathology at the Charing Cross Hospital Medical School. Pp. 372. London: Churchill. 1860.

Dr. Sarter must by this time be well known to the readers of the British medical periodicals as the author of several highly valuable essays on various points connected with asthma; several of which have appeared in this Jounnal. It would have been a matter to be regretted, had these communications been allowed to lie scattered bere and there in the pages of our weekly and monthly literature; but all anxiety which may have been felt on this ground is now removed, by their collection and arrangement, together with such matter as was required for the perfection of the work, into the complete and systematic monograph before us.

The book contains fifteen Chapters and an Appendix. The subjects of the Chapters are:-I, Inquiry into the Tenability of the Theories of Asthma; Ir, The Pathology of Asthma-its Absolute Nature; III, and Iv, Clinical History of Asthma; $\mathrm{v}$, Varieties of Asthma; vi, Etiology of Asthma; vir, Consequences of Asthma; vIII, $\mathrm{IX}, \mathrm{x}$, and $\mathrm{XI}$, Treatment of the Asthmatic Paroxysm; xII, Dietetic and Regiminal Treatment of Asthma; xIII, The Therapeutical Influence of Localities; xIv, Hygienic Treatment of Asthma ; xv, Prognosis of Asthma. The Appendix consists of eleven narrated cases, and forty-four tabulated cases.

In the first chapter, Dr. Salter examines the theories which have been held as to the nature of asthma. These may be briefly enumerated as follows:- 1 , That contraction of the bronchial tubes is not necessary to produce asthma (Laennec, Copland, and Walshe; regarding whose theories Dr. Salter holds that the "asthma with puerile breathing" of Laennec, the " nervous asthma" of Copland, and the "bæmic asthma" of Walshe, are forms of dyspncea, not true asthma); 2 , that the asthmatic paroxysm is an effort to get rid of irritating matter in the air-tubes (Dr. Bree); 3, that asthma is a phe nomenon of a peculiar form of bronchitis (bronchite $\dot{a}$ rales vibrants, M. Beau ); 4 , that the essence of asthma is humoralthat each attack depends on the development of some specific humoral disturbance; 5, that asthma depends upon a poisoning of the nerves of respiration or of the portions of the nervous centres with which they are connected, by a particular materies morbi (Dr. Told); 6 , that one form of asthma is nothing but the dyspnoa of emphysema, and that another is but a spasm or suspension of the normal action of the muscles of inspiration (Dr. Budd) ; 7, that asthma depends not upon spasm, but on paralysis of the bronchial tubes; 8 , that there is no such thing as asthma as a substantive disease.

Having ably demonstrated the insufficiency of these numerous and often conflicting hypotheses, the author proceeds in the second chapter to develope what he believes to be the true pathology of asthma. His views on this subject are:-

“ 1 . Asthma is essentially, and, with perhaps the exception of a single class of cases, exclusively, a nervous disease; the nervous system is the seat of the essential pathological condition.

" 2 . The phenomena of asthma-the distressing sensation, and the demand for extraordinary respiratory efforts-immediately depend upon a spastic condition of the fibro-cells of organic or unstriped muscle, which minute anatomy has demonstrated to exist in the bronchial tules.

" 3 . These phenomena are those of excito-motory reflex action.

" 4 . The extent to which the nervous system is involved differs very much in different cases, being in some cases re. stricted to the nervous system of the air-passages themselves. 